\title{
Growth Hormone (GH) Treatment in GH-Deficient Adults; Therapeutic and Diagnostic Aspects
}

Anders Juul, Jens Otto L. Jørgensen, Jens S. Christiansen, Jørn Müller and Niels E. Skakkebæk

Department of Growth and Reproduction, University of Copenhagen (A.J., J.M., N.E.S.), Department of Internal Medicine (diabetes and endocrinology)(J.O.L.J., J.S.C.), University of Aarhus, Denmark

\begin{abstract}
Adults with GH-deficiency have increased mortality due to cardiovascular disease and share several clinical signs, such as reduced muscle strength, reduced exercise capacity, reduced sweating ability and thermoregulation, subnormal kidney function, reduced myocardial function, reduced energy expenditure, abnormal thyroid hormone metabolism, impaired psychosocial well-being, decreasing lean body mass and decreased bone mineral content. All studies have unanimously shown that GH replacement therapy in GH-deficient adults have improved all the above reported clinical symptoms.

We conclude that GH-deficiency in adults is associated with a number of subnormal features. GH treatment improves (normalizes) these symptoms and we therefore believe that GH replacement therapy of a GH-deficient individual should be continued after cessation of linear growth. However, treatment of such patients should be carefully monitored since data from follow-up studies are still lacking.
\end{abstract}

Key words: adult GH deficiency syndrome, GH treatment, diagnosis, bone mineral content, exercise performance, sweating, thermoregulation, lean body mass

\section{Introduction}

The potential of growth hormone $(\mathrm{GH})$ treatment to promote linear growth in $\mathrm{GH}$ deficient children is well recognized. Furthermore, pronounced metabolic effects are seen during $\mathrm{GH}$ treatment of children with $\mathrm{GH}$ -

Correspondence: Dr. Niels E. Skakkebæk, Department of Growth and Reproduction, Section GR-5064, National university Hospital, 9, Blegdamsvej, DK-2100 Copenhagen Denmark deficiency in terms of improved bone density, fat distribution and glucose metabolism. Most of these results have been accomplished by the use of extracted pituitary hGH. With the recent advent of biosynthetic human GH wider indications for treatment of children with $\mathrm{GH}$ are now possible.

Due to the limited supply of pituitaryderived $\mathrm{GH}$, it has not previously been practicable to continue $\mathrm{GH}$ replacement therapy beyond the cessation of linear growth in the adolescent period. Neither has it been well 
examined what the consequences of withdrawal of $\mathrm{GH}$ replacement in this critical period might be. During the last five-year period, a substantial amount of data have shown that there are subnormal features in GH-deficient adults that can be normalized if $\mathrm{GH}$ replacement therapy is reinitiated.

Normal aging is associated with a gradual decline in GH secretion [1] accompanied by a reduced bone mineral content and lean body mass, and an increased fat mass, a phenomenon referred to as the somatopause. In this respect, there are several resemblances between physiological aging and adult GHdeficiency, and GH treatment has actually been attempted in healthy elderly people [2, $3]$. However, these aspects of $\mathrm{GH}$ treatment must be clearly segregated from treatment of adults with verified "true" $\mathrm{GH}$ deficiency. In this paper we will describe only the typical features of adult patients with "true" GHdeficiency and the potential effects of $\mathrm{GH}$ treatment.

\section{Features of the adult GH-deficiency syndrome and effects of GH}

Cardiovascular system: GH-deficient patients have myocardial dysfunction $[4,5]$ and increased incidence of atherosclerosis [6, 7] associated with an increased mortality due to cardiovascular disease [8]. GH treatment has increased cardiac output [9] and has been reported to decrease cholesterol and low density lipoprotein concentrations and to increase high density lipoprotein concentrations [10]. GH thus seems to affect cardiovascular function and to regulate lipoprotein metabolism in adults with GH-deficiency.

Renal effects: Glomerular filtration rate and renal blood flow were significantly increased (normalized) after GH treatment [9]. Furthermore, a significant activation of the renin-angiotensin-aldosterone system has been demonstrated in GH-deficient adults [11]. This is in line with the reduction in atrial natriuretic peptide after $\mathrm{GH}$ treatment of normal men [12].

Thyroid function: It is now well recog- nized that $\mathrm{GH}$ exerts an important action on peripheral iodothyronine metabolism in terms of stimulation of extrathyroidal conversion of thyroixine (T4) to triiodothyronine (T3). More interestingly, it has been demonstrated that adult GH-deficient patients exhibit subnormal T3 levels (in spite of normal T4 levels), which become normalized with $\mathrm{GH}$ substitution [13]. We believe that this action of GH contributes to its overall anabolic effects, especially when keeping in mind that Sato et al. [14] have reported a linear correlation between T3 levels and linear growth in GHtreated GH-deficient children.

Bone: A reduced bone mineral content was demonstrated in untreated adults with GH deficiency of childhood or pubertal onset $[15,16]$ as well as in patients with $\mathrm{GH}$ deficiency acquired later in life [17], explaining, at least partly, the increased prevalence of osteoporosis in GH-deficiency [7]. There is some controversy on the possible effects of GH replacement therapy on bone in the adult state. Several studies have indicated increased bone turnover in GH-deficient adults during $\mathrm{GH}$ replacement therapy, in terms of increments in serum concentrations of bone Glaprotein [18] and procollagens [19] and in urinary excretion of calcium, hydroxyproline and pyrridinoline cross-links [20]. However, the effect of $\mathrm{GH}$-induced increase in bone turnover on bone mineral content (BMC) is not clear. Most studies have failed to show an increase in BMC after $\mathrm{GH}$ treatment for up to 6 months [21,22,23]. However, a recent open trial reported an increase in BMC after 12 months of GH therapy [24]. This discrepancy we believe is due to the need for longer treatment periods before a beneficial effect on BMC can be seen.

Body composition: GH-deficient adults have a decreased lean body mass and a decreased muscle/fat ratio as demonstrated by various methods, such as cross-sectional CT scan of the thign [9], bioelectrical impedance $[22,25]$ and total body potassium assessment $[22,26]$. A decreased extracellular fluid volume has also been reported in these patients 


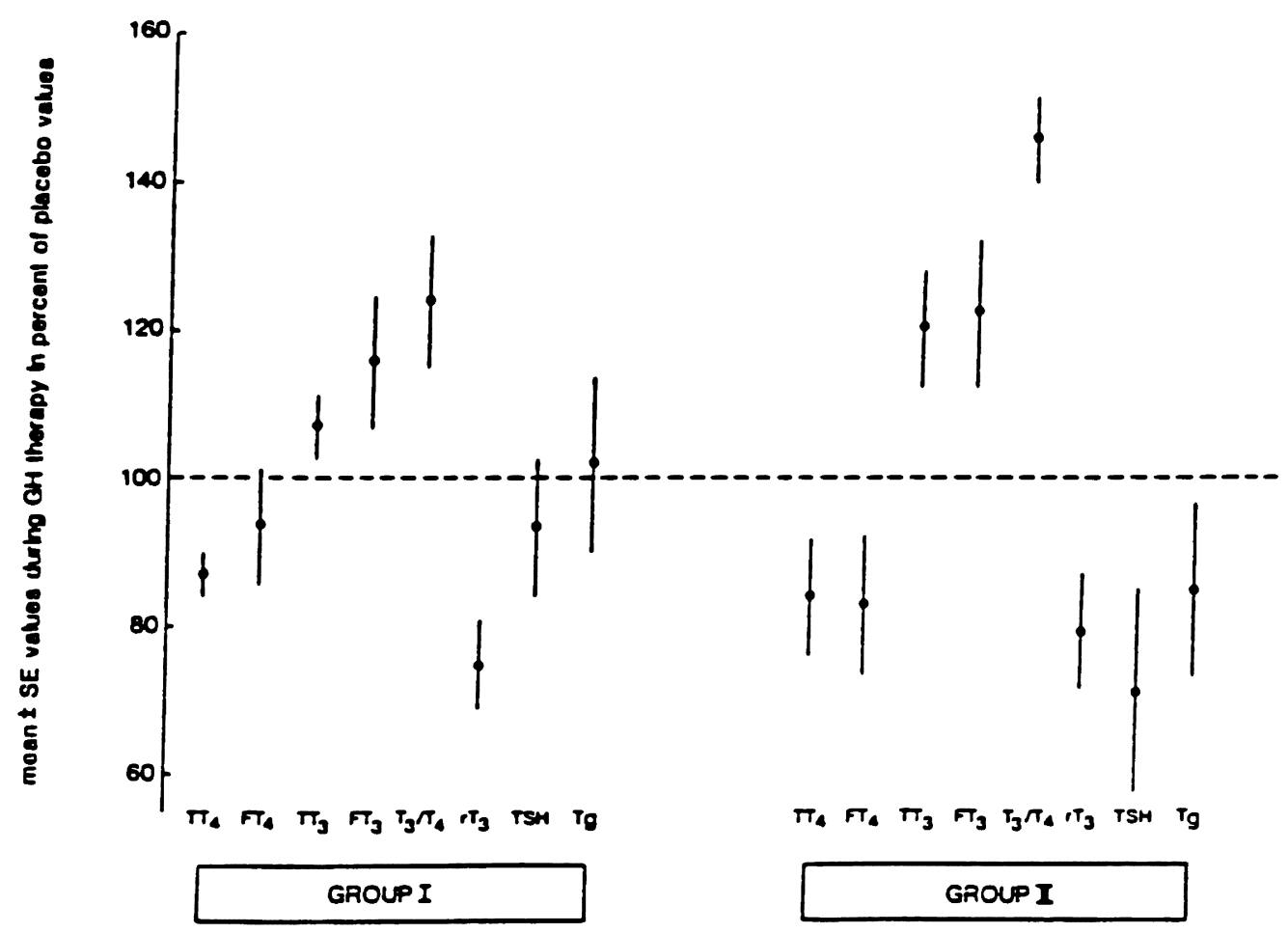

Fig. 1. Mean $( \pm \mathrm{SE})$ levels of circulating iodothyronines, TSH, Tg and T3/T4 ratio in GH-deficient adults not receiving T4 therapy (group I) and receiving T4 therapy (group II) at the end of a 4-month GH treatment period, expressed as percent change from the corresponding levels at the end of a placebo period. Data are derived from reference [13].

[26]. Furthermore, a reduced energy expenditure has been described [27] possibly due to the decreased lean body mass. In all studies, it has been agreed that GH treatment has increased lean body mass and improved the muscle/fat ratio in GH-deficient adults $[9,19$, $21,22,23,24,28,29,39]$.

Muscular performance: Reduced exercise capacity $[28,30]$ as well as reduced muscle strength [28] was demonstrated in $\mathrm{GH}$ deficient adults, although histological studies of skeletal muscles showed no signs of myopathy [31]. GH treatment improved exercise capacity $[9,27,28]$ as well as muscle strength $[9,30]$.

Reproduction: Male patients with isolated GH-deficiency had moderately reduced semen quality, and short-term treatment with $\mathrm{GH}$ did not result in any significant improvement [32]. The potential role of GH and IGFs on reproductive endocrinology is subject to inten- sive research.

Sweating and temperature regulation: Hyperhidrosis is a classic symptom of acromegaly, and conversely, patients with GH deficiency show reduced sweating, as determined by the pilocarpine iontophoresis method. After 4 months of $\mathrm{GH}$ treatment sweating increased significantly towards normal [33]. Sweating is important for maintenance of body temperature during exercise or heat exposure. A report on unexplained hyperthermia in 3 untreated adults with GH deficiency [34] indicates that GH may indeed play a role in sweating and thermoregulation. A recent study revealed that during moderate heat exposure, 6 young adults with GH deficiency had a reduced evaporative heat loss and theraby a greater body heat storage, compared to 6 matched healthy subjects (figure 1). Two of the 6 patients reacted with severe clinical symptoms of heat exhaustion, 


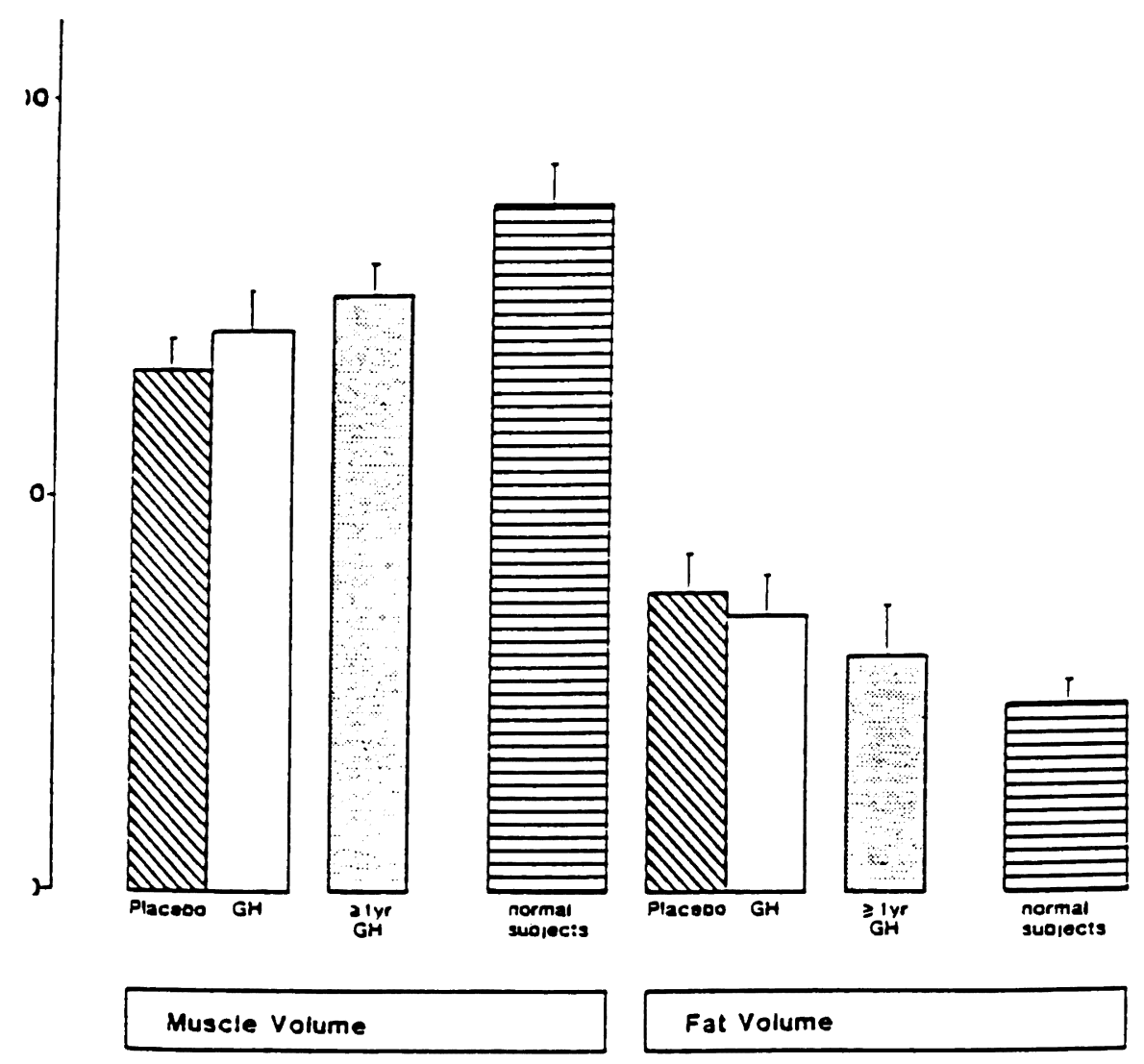

Fig. 2. Muscle and fat volume of the high in GH-deficient patients during a shortterm GH trial and after more than 1 year of $\mathrm{GH}$ treatment, compared to normal subjects, expressed as $\mathrm{ml} / 0.8 \mathrm{~cm}$ cross-sectional slice. Bars represent mean (SE). Data are derived from reference [28].

whereas the controls were unaffected. After exercise the patients reached significantly higher core temperatures than the controls [35]. It remains to be seen whether $\mathrm{GH}$ treatment can improve thermoregulatory function.

Psychosocial aspects: Follow-up studies of adults treated with $\mathrm{GH}$ in childhood have shown a high risk of unemployment and a low marital rate [36,37]. Assessment of psychological well-being in GH-deficient adults revealed that they perceive themselves as having physical and psychological problems [38]. GH treatment improves perception of energy level, mental alertness and mood $[38,39]$. The mechanisms by which $\mathrm{GH}$ exerts its psychological effect are difficult to determine. Improved physical well-being itself might have an effect, or it could be an improved cerebral blood flow. Finally, a direct cerebral effect of GH or IGF. I cannot be excluded. The latter hypothesis is supported by the improvement of abnormal sleep pattern seen after $\mathrm{GH}$ treatment [40].

\section{Diagnosis of GH-deficiency}

Children: There are many problems in diagnosing $\mathrm{GH}$ deficiency in poorly growing children. In a recent paper it was demonstrated that 33 of 63 children previously diagnosed as GH-deficient by means of classic pharmacological and sleep tests did not have a true deficiency when retested, and 13 of these (21\%) were considered to have a normal GH response. However, the children who appear- 


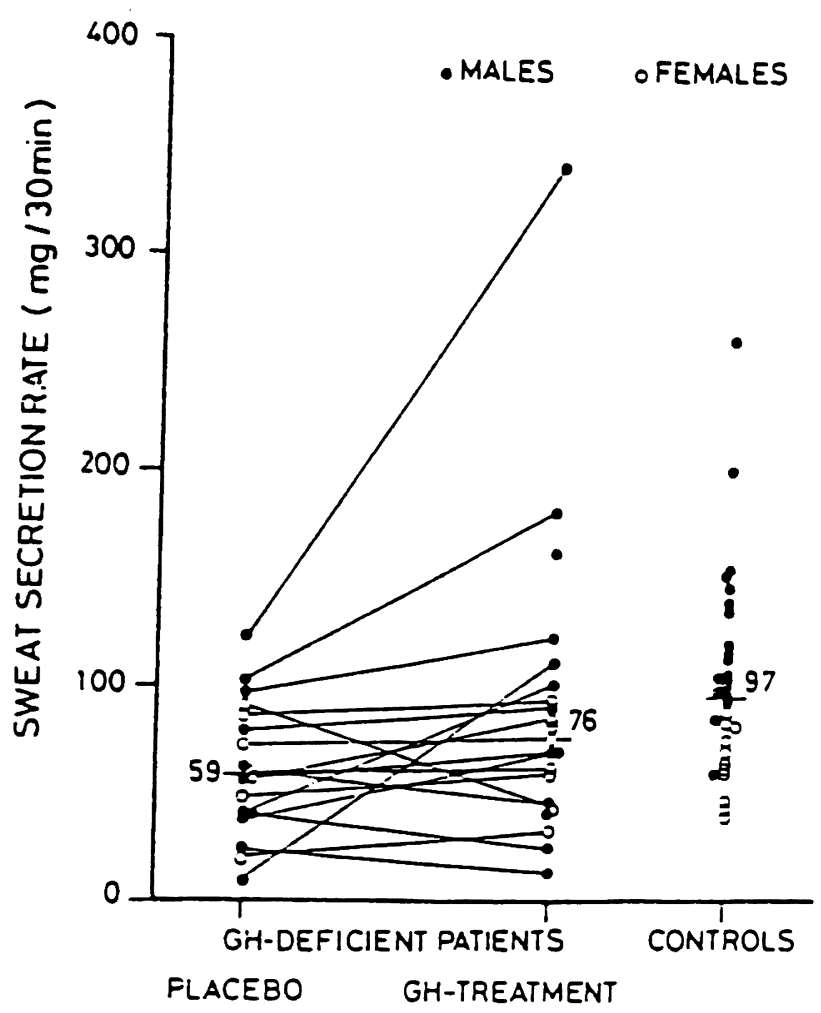

Fig. 3. Sweating secretion rates determined by the pilocarpine iontophoresis method, after 4 months of GH treatment in GH-deficient adults, compared to healthy subjects. Median values are shown. Data are derived from reference [33].

ed to be normal when retested did not grow differently from those who were still GHdeficient [41]. Therefore, the diagnosis does not per se indicate which children will benefit from GH treatment, and very strict criteria for subdividing poorly growing children according to their maximal $\mathrm{GH}$ response to a provocative test may not be justified. However, this is not the case for adults. We strongly believe that, in the present era of adult GH treatment, very strict criteria for diagnosing adults with $\mathrm{GH}$ deficiency should be put forward.

Adults: Obviously, some of the potential candidates for adult $\mathrm{GH}$ replacement therapy have been diagnosed in childhood due to growth deficit and have subsequently been treated with GH. When diagnosing adults with GH deficiency or confirming the diag- nosis in adult patients with GH deficiency of childhood onset, we have to rely on clinical data (specific features of GH deficiency), laboratory measurement and provocative tests, since auxological data do not support the diagnosis in adults, as they do in children. This suggests some potential pitfalls, which have to be dealt with in the future:

\section{Provocative test:}

a. Definition of specific cut-off value following a $\mathrm{GH}$ provocative test for each laboratory.

Due to the heterogeneity of circulating $\mathrm{GH}$ forms, each $\mathrm{GH}$ assay may prosereact with these $\mathrm{GH}$ forms to a different extent, and therefore it is of the outmost importance that each laboratory construct its own normal cutoff value [42].

b. Age-dependence of endogenous GH secretion.

Normal aging is associated with a gradual decline in integrated 24-hour GH secretion [1]. Therefore, the use of a fixed cut-off level in a classical GH provocative test is thought to be inadequate.

c. $\mathrm{GH}$ responsivity to provocative test during the menstrual cycle.

$\mathrm{GH}$ responsivity to a provocative test is strongly dependent on sex steroids, and the $\mathrm{GH}$ response is very dependent on the time of the menstrual cycle [43].

\section{Basal serum IGF-I and IGFBP-3:}

Serum levels of IGF-I and IGFBP-3 reflect the integrated 24-hour $\mathrm{GH}$ secretion and have proven to be reliable indices of $\mathrm{GH}$ secretion and linear growth in children. Less is known about the diagnostic value of these parameters in adults. Serum levels of IGF- I exhibit, like integrated serum GH concentrations, a gradual decline with increasing age in healthy adults [1] as do serum levels of IGFBP-3 [44]. This implicates that a hypothetical IGF- I concentration of $150 \mu \mathrm{g} / \mathrm{L}$ is below the normal range for a 20-year-old patient but in the middle part of it if the patient is 70 years old. It emphasizes the 
JUUL et al.
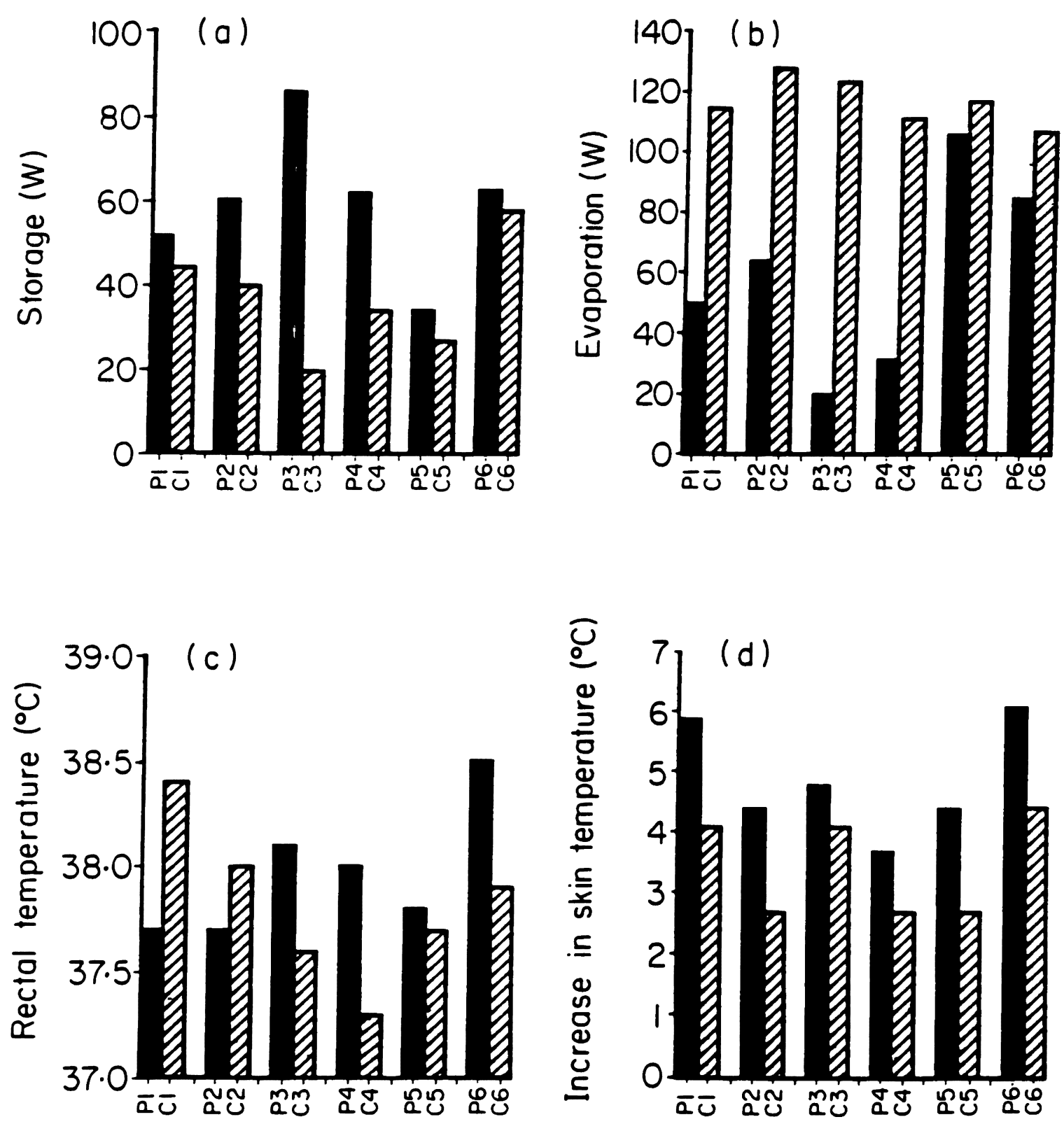

Fig. 4. Heat calculations and temperatures after 90-minute heat exposure $(40 \mathrm{C})$ in $6 \mathrm{GH}$-deficient adults (P1-P6) compared to matched control subjects (C1-C6). a) Heat storage, b) evaporation, c) rectal temperature and d) skin temperature. Data are derived from reference [35].

importance of a large reference material, when using serum concentrations of IGF. I and IGFBP-3 as diagnostic tools in adults.

We therefore propose that a definition of the adult GH deficiency syndrome should at least include:

1. Insufficient response to classical stimulation tests (taking into account age, stage in menstrual cycle, and assay-specific cut-off values)

2. Serum IGF-I and IGFBP-3 below the normal range for age (large reference meterial required)

3. GH deficiency since childhood $\frac{\text { or }}{2}$

4. If $\mathrm{GH}$ deficiency acquired in adulthood, additional deficiency of at least one of 
ACTH, LH/FSH of TSH, or known reason for GH-deficiency (intracranial tumour).

\section{Concluding remarks}

GH deficiency in adults is associated with a number of clinical symptoms. GH treatment improves or normalizes these symptoms. Therefore, we believe that GH treatment should be continued in adulthood in GHdeficient patients. However, the results of ongoing, long-term GH studies of GH-deficient adults should be obtained before a final decision can be made.

\section{References}

1. Ho KY, Evans WS, Blizzard RM, et al.: Effects of sex and age on the 24-hour profile of growth hormone secretion in man: importance of endogenous estradiol concentrations. J Clin Endocrinol Metab 1987; 64: 51-8.

2. Rudman D, Feller AG, Nagraj HS, et al.: Effects of human growth hormone in men over 60 years old. N Engl J Med 1990; 323: 1-6.

3. Marcus R, Butterfield G, Holloway I: Effects of short term administration of recombinant human growth hormone to elderly people. J Clin Endocrinol Metab 1990; 70: 519-27.

4. Shahi M, Beshyah SA, Hackett D, Sharp PS, Johnston DG, Foale RA: Myocardial dysfunction in treated adult hypopituitarism: a possible explanation for increased cardiovascular mortality. Br Heart J 1992; 67: 92-6.

5. Johnston DG, Beshyah SA, Markussis V, et al.: Metabolic changes and vascular risk factors in hypopituitarism. Horm Res 1992; 38 (suppl 1): 68-72.

6. Markussis V, Beshyah SA, Fisher C, Sharp P, Nicolaides AN, Johnston DG: Detection of premature atherosclerosis by highresolution ultrasonography in symptom- free hypopituitary adults. Lancet 1992; 340: 1188-92.

7. Wüster C, Slenczka E, Ziegler R: Erhöhte Prävalenz von Osteoporose und Arteriosklerose bei konventionell substituierter Hypophysenvorde lappeninsuffizienz: Bedarf einer zusätzlichen Wachstumshormonsubstitution? Klin Wochenschr 1991; 69: 769-73.

8. Rosén T, Bengtsson B-Å: Premature mortality due to cardiovascular disease in hypopituitarism. Lancet 1990; 336: 285-8.

9. Jørgensen JOL, Pedersen SA, Thuesen L, et al.: Beneficial effects of growth hormone treatment in GH-deficient adults. Lancet 1989; i: 1221-5.

10. Edén S, Wiklund O, Oscarsson J, Rosén T, Bengtsson B-Å: Growth hormone treatment of growth hormone-deficient adults results in a marked increase in $\operatorname{Lp}(a)$ and HDL cholesterol concentrations. Arterioscl Thromb 1993; 13: 296-301.

11. Cuneo RC, Salomon F, Wilmhurst P, et al.: Cardiovascular effects of growth treatment in growth-hormone-deficient adults: stimulation of the renin-aldosterone system. Clin Sci 1991; 81: 587-92.

12. Møller J, Jørgensen JOL, Møller N, Hansen kw, Pedersen EB, Christiansen JS: Expansion of the extracellular volume and suppression of atrial natriuretic peptide after growth hormone administration in normal man. J Clin Endocrinol Metab 1991; 72: 768-72.

13. Jørgensen JOL, Pedersen SA, Laurberg P, Weeke J, Skakkebæk NE, Christiansen JS: Effects of growth hormone therapy on thyroid function of growth hormone-deficient adults with and without concomitant thyroxine-substituted central hypothyroidism. J Clin Endocrinol Metab 1989; 69: 1127-32.

14. Sato T, Suzuki $\mathrm{Y}$, Taketani $\mathrm{T}$, et al.: Enhanced peripheral conversion of thyroxine to triiodothyronine during $\mathrm{hGH}$ therapy in GH deficient children. J Clin Endocrinol Metab 1977; 45: 324-9.

15. Hyer SL, Rodin DA, Tobias JH, Leiper A, 
Nussey SS: Growth hormone deficiency during puberty reduces adult bone mineral density. Arch Dis Child 1992; 67: 1472-4.

16. Kaufman J-M, Taelman P, Vermeulen A. Vandeweghe M: Bone mineral status in growth hormone-deficient males with isolated and multiple pituitary deficiencies of childhood onset. J Clin Endocrinol Metab 1992; it: 118-23.

17. Bing-You RG. Denis M-C, Rosen CJ: Low bone mineral density in adults with previous hypothalamic-pituitary tumors: correlations with serum grwoth hormone responses to GH-releasing hormone, insulin-like growth factor I, and IGF binding protein 3. Calcif Tissue Int 1993; 52 : $183-\bar{T}$.

18. Johansen JS, Giwercman A. Hartwell D. et $a l$.: Serum bone Gla-protein as a marker of bone growth in children and adolescents: correlation with age, height, serum insulinlike growth factor I and serum testosterone. J Clin Endocrinol Metab 1988; 67: 273-8.

19. Bengtsson B-A, Edén S, Lönn et al .: Treatment of adults with growth hormone (GH) deficiency with recombinant human GH. J Clin Endocrinol Metab 1993; 76: 309-17.

20. Schlemmer A. Johansen JS, Pedersen S.A. Jorgensen JOL, Hassager C: The effects of growth hormone on urinary pyrridnoline cross-links in GH-deficient adults. Clin Endocrinol 1991; \$i1-6.

21. Whitehead HM, Boreham C, Mcl lrath EM. et al.: Growth hormone treatment of adults with growth hormone deficiency: results of a 13-month placebo-controlled cross-over study. Clin Endocrinol 1992; 36: 45-j2.

22. Binnerts A. Swart GR, Wilson JHP. et al : The effect of growth hormone administration in growth hormone deficient adults on bone, protein, carbohydrate and lipid homeostasis, as well as on body composition. Clin Endocrinol 1992; 37: 79-87.

23. Orme S.M, Sebastian JP, Oldroyd B, et al :: Comparison of measures of body composition in a trial of low dose growth hormone replacement therapy. Clin Endocrinol
1992; 37: 453-9.

24. Degerblad M, Elgindy N, Hall K, Sjōberg H-E, Tohrén M: Potent effect of recombinant growth hormone on bone mineral density and body composition in adults with panhypopituitarism. Acta Endocrinol 1992; 126: 387-93.

25. De Boer H, Blok GL, Voerman HJ, De Vries PMJM, Van der Veen EA: Body composition in adult growth hormonedeficient men, assessed by anthropometry and bioimpedance analysis. $J$ Clin Endocrinol Metab 1992; 75: 833-7.

26. Rosén T, Bosaeust I, Tölli J, Lindstedt G, Bengtsson B- $\mathrm{A}$ : Increased body fat mass and decreased extracellular fluid volume in adults with growth hormone deficiency. Clin Endocrinol 1993; 38: 63-71.

27. Cuneo RC, Salomon F, Wiles CM, Hesp R, Sōnksen PH: Growth hormone treatment n growth hormone-deficient adults. II. Effects on exercise performance. J Appl Physiol 1991; 70: 695-700.

28. Jorgensen JOL, Pedersen SA, Thuesen L, et al.: Long-term growth hormone treatment in growth hormone deficient adults. Acta Endocrinol 1991; 125: 44953.

29. Salomon F, Cuneo RC, Hesp R, Sönksen PH: The effects of treatment with recombinant human growth hormone on body composition and metabolism in adults with growth hormone deficiency. I Engl J Med 1989; 321: 1797-803.

30. Cuneo RC, Salomon F. Wiles MC, Hesp R, Sönksen PH: Growth hormone treatment in growth hormone-deficient adults. I . Effects on muscle mass and strength. J Appl Physiol 1991: T0: 688-94.

31. Cuneo RC, Salomon F. Wiles CM, et al.: Histology of skeletal muscle in adults with GH deficiency: comparison with normal muscle and response to GH treatment. Horm Res 1992; 37: 23-8.

32. Pedersen S.A. Jorgensen JO, Christiansen JS, Jensen S, Jelnæs JE, Skakkebæk NE: Growth hormone and reproduction: reduced semen quality in men previously treated for growth hormone deficiency. In: 
Hormonal regulation of growth. Frisch $\mathrm{H}$, Thorner MO, eds. New York: Raven Press, 1989; 273-82.

33. Pedersen SA, Welling K, Michaelsen KF, Jørgensen JO, Christiansen JS, Skakkebæk NE: Reduced sweating in adults with growth hormone deficiency. Lancet 1989; ii: $681-2$.

34. Juul A, Skakkebæk NE: Growth hormone deficiency and hyperthermia. Lancet 1991; 338: 887.

35. Juul A, Behrenscheer A, Tims T, Nielsen B, Halkjær-Kristensen J, Skakkebæk NE: Impaired thermoregulation in adults with growth hormone deficiency during heat exposure and exercise. Clin Endocrinol 1993; 38: 237-44.

36. Dean HJ, McTaggart TL, Fish DG, Friesen HG: The educational, vocational, and marital status of growth hormone deficient adults treated with growth hormone during childhood. Am J Dis Child 1985; 139: 1105-10.

37. Björk S, Jönsson B, Westphal O, Levin J-E: Quality of life of adults with growth hormone deficiency: a controlled study. Acta Paediatr Scand [Suppl] 1989; 356: 55-9.

38. McGauley GA: Quality of life assessment before and after growth hormone treatment in adults with growth hormone deficiency. Acta Paediatr Scand [Suppl] 1989; 356: 70-2.
39. Degerblad M, Almkvist O, Grunditz R, et al.: Physical and psychological capabilities during substitution therapy with recombinant growth hormone in adults with growth hormone deficiency. Acta Endocrinol 1990; 123: 185-93.

40. Astrand C, Pedersen SA, Lindholm J: The influence of growth hormone on sleep in adults with growth hormone deficiency. Clin Endocrinol 1990; 33: 495-500.

41. Cacciari E, Tassoni P, Parisi G, et al.: Pitfalls in diagnosing impaired growth hormone $(\mathrm{GH})$ secretion: retesting after replacement therapy of 63 patients defined as GH deficient. J Clin Endocrinol Metab 1992; 74: 1284-9.

42. Dattani MT, Pringle PJ, Hindmarsh PC, Brook CGD: What is a normal stimulated growth hormone concentration? J Endocrinol 1992; 133: 447-50.

43. O'Keane V, Dinan TG: Sex steroid priming effects on growth hormone response to pyridostigmine troughout the menstrual cycle. J Clin Endocrinol Metab 1992; 75: 11-4.

44. Blum WF, Ranke MB, Kietzmann K, Gauggel E, Zeisel HJ, Bierich JR: A specific radioimmunoassay for the growth hormone (GH)-dependent somatomedinbinding protein: its use for diagnosis of $\mathrm{GH}$ deficiency. J Clin Endocrinol Metab 1990; 70: $1292-8$. 